\title{
AUTOMATED DIGITAL ODONTOMETRY: MEASUREMENT DATA ANALYSES IN CASES OF COMPLICATED DENTAL MORPHOLOGY
}

\author{
A.V. Gaboutchian ${ }^{1,}{ }^{*}$, V.A. Knyaz ${ }^{2,3}$, M.M. Novikov ${ }^{5}$, S.V. Vasilyev ${ }^{4}$, N.A. Leybova ${ }^{4}$, \\ D.V. Korost ${ }^{6}$, S.A.Cherebylo ${ }^{5}$, A.A. Kudaev ${ }^{6}$ \\ ${ }^{1}$ Peoples' Friendship University of Russia, 117198, Moscow, Russia - armengaboutchian@mail.ru \\ ${ }^{2}$ State Research Institute of Aviation System (GosNIIAS), 125319 Moscow, Russia - knyaz@ gosniias.ru \\ ${ }^{3}$ Moscow Institute of Physics and Technology (MIPT), Russia \\ ${ }^{4}$ Institute of Ethnology and Anthropology of Russian Academy of Sciences , 119991, Moscow, Russia - \\ vasbor1@yandex.ru; nsuvorova@mail.ru \\ ${ }^{5}$ Institute on Laser and Information Technologies of RAS -Branch of Federal Scientific Research Centre "Crystallography and \\ Photonics” of RAS, Shatura, Russia - novikov@ rambler.ru ; svetlana.cherebylo@ rambler.ru \\ ${ }^{6}$ Faculty of Geology, Moscow State University, 119234, Moscow, Russia - dkorost@ mail.ru ; tyrka1995@mail.ru
}

\section{Commission II, WG II/10}

KEY WORDS: automated digital odontometry (aDo), 3D surface analysis, palaeoanthropology, odontology

\begin{abstract}
:
3D imaging techniques, which started to be exact in regard to the current study with photogrammetry, have brought to development of measurement method - automated digital odontometry ( $\mathrm{aDo}$ ) - with wider opportunities in terms of understanding morphological characteristics of human (or, non-human) teeth and dentition. Revealing them through odontometric parameters, not as visual descriptions, as it has been accepted for decades and is widespread till today, digital measurement methods provide for various previously unattainable detailed objective studies including descriptions or comparisons. These types of studies, carried out for dental and anthropological applications, are of high demand in palaeoanthropology, especially in cases of rare combination of finding uniqueness and preservation degree with considerations of unusual morphology. Thus odontological samples from the Upper Palaeolithic Sunghir' (individual C2) are of particular interest in the current study which is aimed to detect distinctive parameters related to morphological features and to compare the degree of feature expression on antimere teeth and teeth with lower degree of that feature expression.
\end{abstract}

\section{INTRODUCTION}

\subsection{Odontometry}

Odontometry has become an integral part of studies related to teeth or dentition in a number of scientific or clinical disciplines, among which the following can be mentioned: biology, anthropology, archaeology and medicine (dentistry). And there are different approaches to conducting measurement, while the most traditional, established and quite often used even in our days is manual (Taduran, 2012; Peckmann et al., 2015; Song et al., 2017). However it has certain limitations, thus currently odontometry is tending towards methods, based on 3D imaging and image processing techniques. In some cases it brings to application of existing manual methods to digital images (Smith et al., 2009; Sassani et al., 2018), which obviously opens for researcher all general positive features of using computers. The other direction for digital odontological studies, implies non metric assessments, based on 3D shape morphometric analysis (Skinner et al., 2010; Zanolli et al., 2018), topographical analysis (Guy et al., 2013) or interesting combinations (Dykes and Pilbrow, 2019), which often keeps up with more sophisticated approaches to obtaining 3D images and usually deals with enamel surface analysis, tooth crown outline analysis, as well as studies of underlying structures - enameldentine junction. With regard to the method proposed in the current study - automated digital odontometry - it can run properly only on $3 \mathrm{D}$ images of teeth, though there is a background and an existing practice of running measurements on real sections of teeth or their images, both in anthropology and in dental studies (Martin, 1983, Khera et al., 1990, Smith et al., 2012). However, the method is based on appropriate morphological interpretations and within their confines it combines digital applicability, as its measuring and especially orientating algorithms do not exist beyond 3D imaging and image analysis techniques, with obtaining metric parameters. With the gradual development of the automated digital odontometry the potential for more profound and objective studies of dental morphology has been revealed.

\subsection{Sunghir': the problem of measuring dental morphology}

The presented odontometric study has been carried out on the maxillary second molars of individual $\mathrm{C} 2$ from the Upper Palaeolithic archaeological site of Sunghir. Remains of the C2 individual were the Southern among found in the grave Nr. 2, representing head-to-head burial of two children. This rich burial contained mammoth tusks and significant amount of carved bone artefacts: beads, necklaces, long spears and darts. Certainly findings from this unique archaeological site were subjected to various studies, and some of them provide evidence of kinship between children (Vasilyev, 2000). Widely prevailing view refers Sunghirians to forms derived from miscegenation of Sapiental and Neanderthal origins, however Russian (and former Soviet) anthropological traditions interpret them also as maternal species of Homo heidelbergensis. So

\footnotetext{
* Corresponding author.
} 
studies of traits, including odontological, referring to taxonomical determinants plays an important role in anthropological studies. In this regard a rare and presumably archaic for Sapiental forms morphological feature of maxillary second molars had been described for individual C2 from Sunghir - elongated vertically cusps with sharp-ended and centrally inclined tips (Zubov, 2000) (Figure 1).

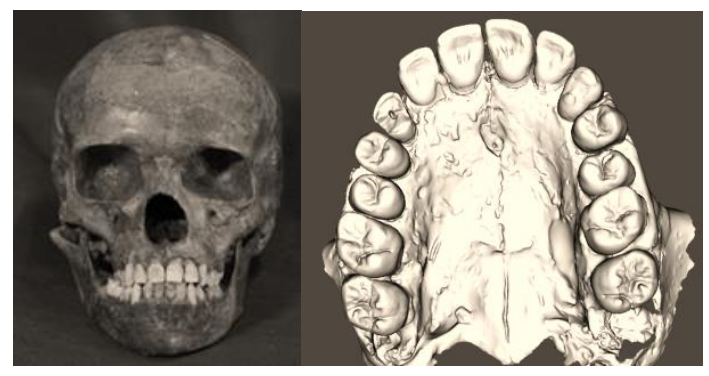

Figure 1. Skull and upper dental arch virtual reconstruction: C2, Sunghir'

This trait has been also described as "centrally placed cusps" and has been found on dentin basis of Neanderthal teeth (Martin et al., 2017). As can be seen, odontological study of the morphological feature has been traditionally held in the nature of descriptive objectivity - as non-metric. Previously these teeth have been studied through angular measurement (Gaboutchian et al., 2019), and the parameters were found to be effective for comparisons with teeth not representing this morphological feature. However, more profound measurements can be performed for odontological analysis of trait expression degree in anthropological research through implementing automated digital odontometry. The studied morphology is characteristic for both upper second molars of the $\mathrm{C} 2$ individual, however with differences in location and expression degree. Thus the upper right molar has bent cusp tips on both orally (or palatally, or lingually) placed cusps; the left studied tooth has the same feature related to vestibularly (or buccally) placed cusps; and only one bent cusp tip on the opposing side of each tooth (Figure 2).

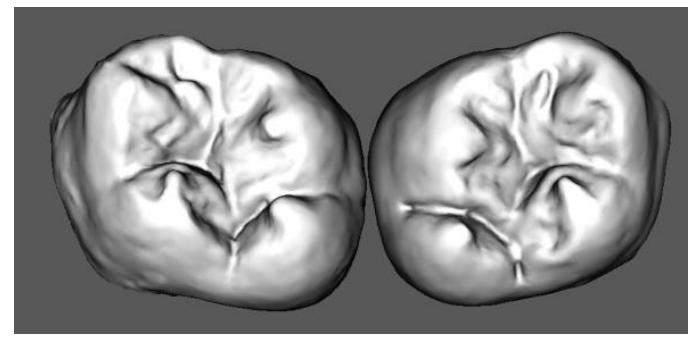

Figure 2. Both upper second molars reconstructed; C2, Sunghir' 1

\subsection{Morphological linkages}

Research interests set out in this study required another tooth with visually evident, however uncommon, trait, the sample for comparisons was taken from craniological series of Chernovaya VIII. It is a typical burial referring to Bronze Age Okunev

\footnotetext{
${ }^{1}$ teeth are facing each other by their oral surfaces; right molar is left on the picture, left tooth is on the right
}

culture, dated back to the second millennium BC, and distributed on the territories of Khakassia and the southern part of Krasnyarsk Krai. Palaeoanthropological material was obtained from 14 kurgan burials in $1962-63$ by G.P. Maximenkov. The Chernovaya VIII series includes 50 skulls and they have been subjected to multiple anthropological studies, including referring to odontological morphology (Zubov, 1980).
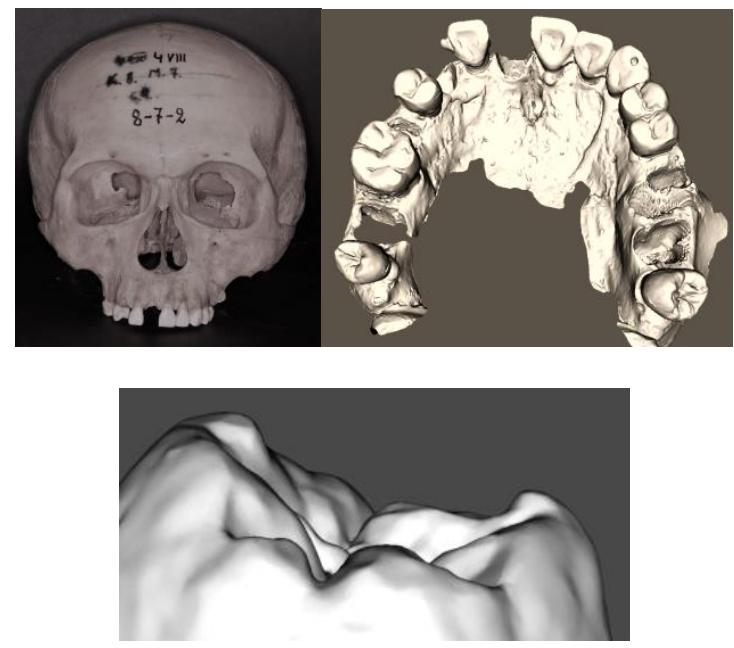

Figure 3. Skull, upper dental arch and the upper left third molar; K8 B7.2, Chernovaya

Thus the current comparative study of $\mathrm{C} 2$ antimere upper second molars and K8 B7.2 upper third molar (Figure 3) is directed to reveal the potential of automated digital odontometry, as the method based on 3D image processing and data analysis, in detection metric parameters referring to morphologically and taxonomically significant odontological traits. This study is also aimed to reveal the directions of improvements for the applied odontometric method. In connection with the above-mentioned intensions and tasks a tooth with completely different morphology and with complete absence of the described features, was taken for comparisons. It is a lower left first molar with moderate attrition; taken from materials obtained at the archaeological site of Fofanovo (Buryatia, Russian Federation), dated through the period of Neolithic, Chalcolithic and Bronze ages (Figure 4).

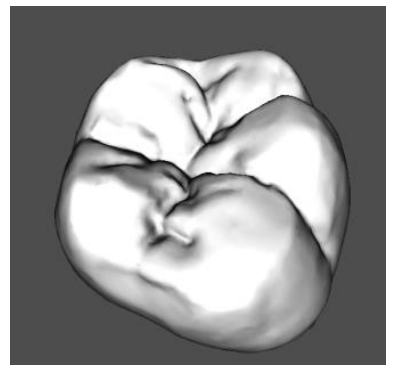

Figure 4. Lower left first molar, Fofanovo

\section{METHODS}

\subsection{D imaging: optical and micro-CT}


Image obtaining methods may vary for aDo application; however scanning accuracy is highly appreciated as it influences directly the measurement results (Gaboutchian and Knyaz, 2019). Initially our 3D imaging experience started with photogrammetry and structured lighting for plaster models of dental arches, nevertheless other scanning methods have been tested and were found to be more suitable for odontological studies of unique palaeoanthropological material. Thus in the current case images partly were obtained by application of intraoral scanner based on confocal optics and special lighting source (Trios, 3Shape). This type of devices, designed predominantly for clinical applications in dentistry, can cope with tooth enamel optical features (taking into consideration its translucency for the majority of conventional lighting sources) without application of opaque coating spray, which is unacceptable for unique material. To some estimates, depending on scanning area, accuracy can approach the level of $30 \mu \mathrm{m}$, providing realistic and detailed images of teeth. Such level of accuracy can be compared with parameters of computed tomographic scans obtained for $\mathrm{C} 2$ individual.

The tomographic method is based on detection of gamma radiation absorption level by passing through different substances. The decrease of gamma ray intensity is fixed on detector from different angles as shade projections - graphical slices in greyscale, which are subsequently recalculated into sets of radiodensity reflecting slices for each studied object and can be used for $3 \mathrm{D}$ volume rendering. Computed tomography image resolution is linked to the object size or rather the diameter of sphere into which the studied object can be placed, thus accurate imaging requires correct positioning of the object in the scanner. By changing the radiation source power the imaging contrast can be set at appropriate level. The C2 skull, with regard to odontological studies, was scanned on GE v|tome $\mid \mathrm{x} \mathrm{m}$ micro-CT system at $275 \mathrm{kV}$ applied to tube providing $43 \mu \mathrm{m}$ accuracy for the scanned volume of the skull which included complete upper dental arch.

\subsection{Processing of tomographic images}

Volume rendering as well as segmentation of teeth and their structures - different in density of tissues, was performed by means of Bruker Corporation software package (CTan, CTvox, CTvol and DataViewer) and Avizo Fire 9.0 software. The obtained images have undergone another stage of processing smoothing. Modes of smoothing applied were selected in order to preserve the accuracy of the virtual reconstruction and are the following: local - by chosen triangles - and global with $90 \%$ strength setting (Magics, Materialise) providing strong associations with previous point location through the adjustment process. Thus point's deviation degree varies within limits of $15 \mu \mathrm{m}$ (Figure 5).

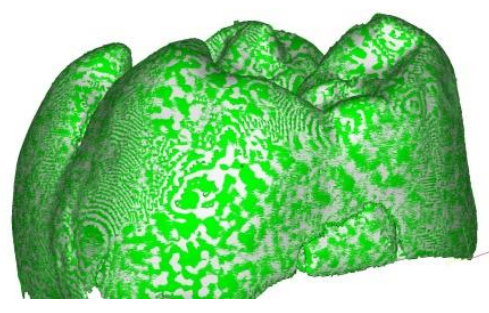

Figure 5. The result of global smoothing procedure for enamel cup surface, C2, Sunghir', tooth 2.7

\subsection{Algorithms of automated digital odontometry (aDo)}

Currently the applied odontometric process goes through stages of tooth orientating with subsequent "slicing", or odontotomy, and measurements on the obtained tooth contours. 3D surface analysis is used at the initial stage for detecting principal morphological structures and setting directions for sectioning procedure according to the estimated characteristics individual for each measured tooth, however general in terms of dental morphology. Similar approaches are applied for measurements on 2D contours for positioning points essential for measurements. Subsequently the measured and calculated parameters are saved and analysed. The above mentioned algorithms are fully automated and if are interrupted, only for operators freedom to choose sectioning mode or for verifying correctness of the performed procedures (Figure 6). Thus the aDo method was applied to the following odontological samples: two antimere upper second molars $-1.7\left(M_{d}^{2}\right)$ and 2.7 $\left(M_{S}^{2}\right)$ of individual C2 from Sunghir', having the highest degree of the studied morphological feature expression; the upper left third molar $2.8\left(M_{S}^{3}\right)$ of an adult individual K8_B7.2 from Chernovaya with low degree of feature expression; and the lower left first molar $3.6\left(M_{1 s}\right)$ with absence of the studied morphological feature. The Sughirian teeth were not only compared with reference samples but with each other as well.
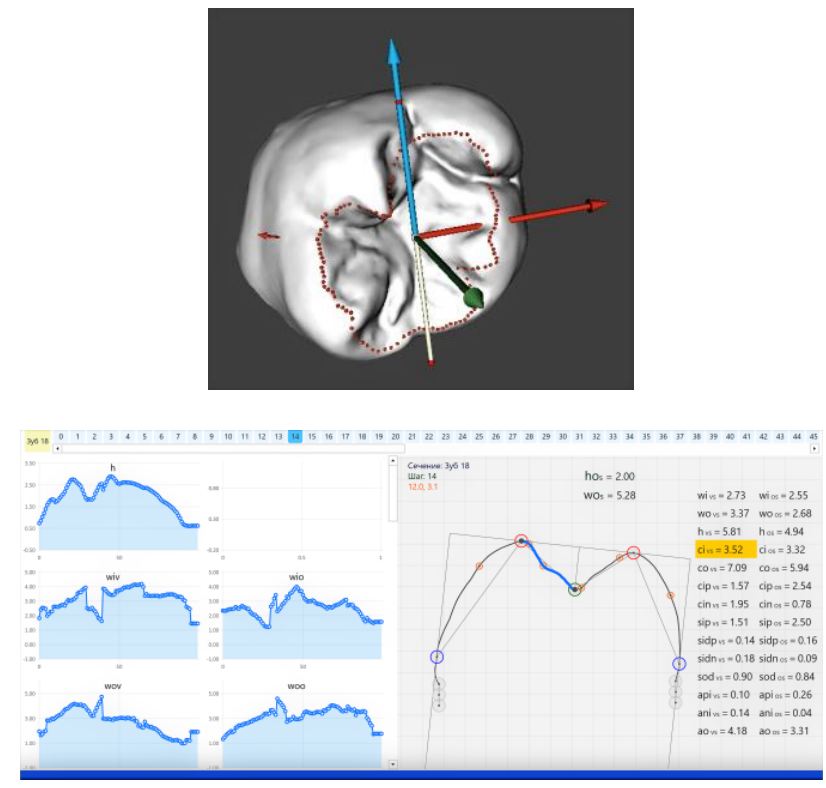

Figure 6. C2 2.7: results of performed orientation (upper) and measurements on contours (lower)

\section{RESULTS AND DISCUSSION}

\subsection{Automated digital odontometry (aDo)}

The described above algorithms, especially referring to orientation (as there are examples of irreversibly destructive sectioning of teeth in "pre-digital" period of anthropological and dental research), work only with $3 \mathrm{D}$ images, and they cannot be implemented on real teeth with expectations of comparable stability and accuracy. Though it is not a unique feature of this very method - there are others: based on shape analysis (Bailey et al., 2014), traditional visual studies (Ortiz et al., 2012) as well as other approaches (Berthaume et al., 2019; Choi et al., 2019). Nevertheless, in line with strong digital 
component, aDo at the same time preserves relevance to substantive dental morphological structures. The suggested morphological interpretations and method development stage allows coverage of significant sector of dental morphological variety, i.e. different teeth (e.g. premolars and molars, upper or lower) and conditions (intact or with significant degree of attrition). Measurements, despite the studied sample variety, are formalised by same algorithms and 3D image processing methods. There is no expertly based measurement landmark setting on teeth or on soft tissues in aDo like in other described techniques (Ghizlanzioni et al., 2017; Oxillia et al., 2017): orientation and measurement algorithms are performed in fully automated mode. Odontometric data can be obtained on any number of teeth and comparisons potentially can be performed with arbitrary number of other measured teeth in relevance to an arbitrary number (from a single to all) of measured parameters. Measured values do not depend on teeth involved in the study, though they depend on their size and morphology. The parameters, obtained through measurements, can be grouped in linear (horizontal, or vestibular-oral, and vertical), contour and angular; some of them are measured, others - calculated. The odontometric data refers to teeth as whole; for each tooth - to cusps, however not separate but grouped (these groups, taking into consideration currently presented samples, include from one to three, but mainly two, cusps) according to their oral or vestibular position; in each group of cusps - to cuspal slopes again, positioned orally and vestibularly (another approach for classifying slopes is outer and inner). We will not provide the whole range of the obtained odontometric data in this paper, only the most relevant in terms of bent cusp tip feature description are presented as summarised, average for whole sets of sections values (Table 1). Another significant structure discussed in the paper is the (anatomic) occlusal surface of teeth formed by inner slopes of cusps; it plays a marked role in morphological interpretations forming the basis of the method (its outlines are presented on Figure 6 as a dotted line).

\subsection{Odontometric data}

Dealing with linear parameters, both Sunghirian molars possess similarities regarding their vestibular-oral dimensions as well as their cusps, except for relatively wider 1.7 oral cusps $-6,57 \mathrm{~mm}$ (their tips, mentioning as a reminder, are noticeably bent). On the level of cusp slopes this observation is supported by wider oral $(3,95 \mathrm{~mm})$ and narrower vestibular slopes $(2,62 \mathrm{~mm})$ of oral cusps on 1.7 if compared to 2.7 tooth $(3,39 \mathrm{~mm}$ and 2,75 $\mathrm{mm}$ respectively). On vestibular cusps a reverse pattern is observed: not much, however wider cusps on 2.7 with wider vestibular slopes; this again is consistent with the observation of more bent cusp tips on 2.7. The opposing, or inner, slopes located centrally on teeth -show tendency to shortening on bent cusps $(2,62 \mathrm{~mm}$ on $1.7 ; 3,04 \mathrm{~mm}-2.7)$. Against the background of two Sunghirian teeth the upper wisdom tooth from Chernovaya differs by its smaller sizes regarding almost all parameters except being the leader in vestibular-oral dimension of its occlusal surface $(6,11 \mathrm{~mm})$, which correlates with low degree of feature expression and relatively shallow cusps in general. We should also mention that all of the studied upper teeth are wider that the lower molar from Fofanovo, not including its comparable sizes of vestibular cusp $(5,65 \mathrm{~mm})$, which is predominantly due to pronounced outer slope (contour length $-5,32 \mathrm{~mm}$ ); however, due to morphology of the masticatory system and orthognathic closure pattern of upper and lower teeth, it is more correct to compare lower vestibular cusps with upper oral.
Another significant part of odontometric data referring to this study subject, as well an extension of our previous studies (Gaboutchian et al., 2019), are angular measurements. And here as well we can find support for the observed dental morphology: the sharpest angle among oral cusp belongs to 1.7 C2 $\left(82,8^{\circ}\right)$. In combination with sharpest angle of inner slope inclination $\left(49,8^{\circ}\right)$ and high/moderate degree of outer slope inclination $\left(33,0^{\circ}\right)$ this values support observation of central inclination of cusps, their bending. Among vestibular cusp, again, the sharpest belongs to $2.7 \mathrm{C} 2\left(81,6^{\circ}\right)$ which is coupled with sharpest angle of inner slope inclination $\left(54,8^{\circ}\right)$ and moderate degree of outer slope inclination $\left(26,8^{\circ}\right)$. It is impossible to ignore gradual increase of occlusal surface angle in sequence: Sunghir' - Chernovaya - Fofanovo, which also corresponds to observations. But how do we get odontometric support for the case with Chernovaya and its moderate expression of the discussed morphological feature? Here, regarding angular measurements, we register peak increase of outer slope inclination on vestibuar cusps $\left(38,0^{\circ}\right)$ and, on the contrary, decrease of outer slope inclination on oral cusps $\left(28,2^{\circ}\right)$, which partly compensates its widely opened occlusal surface. Within a broader scope we can describe this as an oral displacement of the occlusal surface.

\begin{tabular}{|c|c|c|c|c|}
\hline & $\begin{array}{l}1.7 \\
\text { C2 }\end{array}$ & $\begin{array}{l}2.7 \\
\text { C2 }\end{array}$ & $\begin{array}{l}2.8 \\
\text { Ch }\end{array}$ & $\begin{array}{c}3.6 \\
F\end{array}$ \\
\hline \multicolumn{5}{|c|}{ linear horizontal, $\mathrm{mm}$} \\
\hline tooth & 12,71 & 12,34 & 10,59 & 9,89 \\
\hline oral cusps (oc) & 6,57 & 6,14 & 5,19 & 4,24 \\
\hline oc oral slopes & 3,95 & 3,39 & 2,08 & 1,24 \\
\hline oc vest.slopes & 2,62 & 2,75 & 3,11 & 3,00 \\
\hline vest. cusps (vc) & 6,14 & 6,20 & 5,40 & 5,65 \\
\hline vc oral slopes & 3,33 & 3,04 & 3,00 & 2,79 \\
\hline vc vest.slopes & 2,80 & 3,16 & 2,40 & 2,86 \\
\hline occl. surface & 5,95 & 5,79 & 6,11 & 5,79 \\
\hline \multicolumn{5}{|c|}{ linear vertical, $\mathrm{mm}$} \\
\hline occl. surface & 2,25 & 2,13 & 1,66 & 1,14 \\
\hline \multicolumn{5}{|c|}{ contour length, $\mathrm{mm}$} \\
\hline tooth & 22,70 & 21,67 & 17,02 & 14,92 \\
\hline oral cusps (oc) & 11,51 & 10,12 & 8,45 & 6,42 \\
\hline oc oral slopes & 7,83 & 6,47 & 4,76 & 3,04 \\
\hline oc vest.slopes & 3,69 & 3,65 & 3,69 & 3,38 \\
\hline vest. cusps (vc) & 11,19 & 11,54 & 8,57 & 8,51 \\
\hline vc oral slopes & 4,30 & 4,05 & 3,83 & 3,19 \\
\hline vc vest.slopes & 6,89 & 7,49 & 4,75 & 5,32 \\
\hline occl. surface & 7,99 & 7,71 & 7,52 & 6,57 \\
\hline \multicolumn{5}{|c|}{ angular, deg } \\
\hline oral cusps (oc) & 82,8 & 86,2 & 90,4 & 95,6 \\
\hline oc oral slopes & 33,0 & 34,2 & 28,2 & 27,6 \\
\hline oc vest.slopes & 49,8 & 52,0 & 62,1 & 68,0 \\
\hline vest. cusps (vc) & 82,2 & 81,6 & 97,9 & 103,9 \\
\hline vc oral slopes & 56,2 & 54,8 & 59,9 & 66,7 \\
\hline vc vest.slopes & 26,0 & 26,8 & 38,0 & 37,2 \\
\hline occl. surface & 106,0 & 106,8 & 122,1 & 134,7 \\
\hline
\end{tabular}

Table 1. Odontometric data: absolute values

As can be seen, absolute values of odontometric parameters form a multi-coloured picture of objective data largely corresponding to observations of dental morphological features. However, analysis of absolute parameter ratios and complex coefficients are no less important, as they partially smooth out differences in sizes of teeth. A very limited, though informative, 
part of calculated parameters is presented in Table 2. And they show similarities, as well as differences between Sunghirian molars with their almost identical (if presented with two decimal places) occlusal surface / tooth ratios; with lowest ratios (corresponding to sharper cusps) on C2 1.7 oral and C2 2.7 vestibular cusps. Moreover, there is a remarkable significant variance in ratio values on different cusps of the lower molar $(2,58$ vs 1,06$)$, which means the presented odontometric data can serve for differentiating groups of teeth, e.g. lower molars from upper molars.

\begin{tabular}{|c|c|c|c|c|}
\hline & $\begin{array}{l}1.7 \\
\text { C2 }\end{array}$ & $\begin{array}{l}2.7 \\
\mathrm{C} 2\end{array}$ & $\begin{array}{l}2.8 \\
\mathrm{Ch}\end{array}$ & $\begin{array}{c}3.6 \\
F\end{array}$ \\
\hline \multicolumn{5}{|c|}{ linear horizontal } \\
\hline \multicolumn{5}{|c|}{ oral cusps } \\
\hline inner / outer slopes & 0,70 & 0,84 & 1,53 & 2,58 \\
\hline \multicolumn{5}{|c|}{ vestibular cusps } \\
\hline inner / outer slopes & 1,22 & 1,01 & 1,36 & 1,06 \\
\hline \multicolumn{5}{|c|}{ occlusal surface } \\
\hline occl.surface / tooth & 0,47 & 0,47 & 0,57 & 0,58 \\
\hline \multicolumn{5}{|c|}{ contour length } \\
\hline \multicolumn{5}{|c|}{ oral cusps } \\
\hline inner / outer slopes & 0,48 & 0,57 & 0,77 & 1,15 \\
\hline \multicolumn{5}{|c|}{ vestibular cusps } \\
\hline inner / outer slopes & 0,63 & 0,55 & 0,86 & 0,62 \\
\hline \multicolumn{5}{|c|}{ occlusal surface } \\
\hline occl.surface / tooth & 0,35 & 0,35 & 0,44 & 0,44 \\
\hline
\end{tabular}

Table 2. Odontometric data: ratios

Nevertheless, we are not aimed to present a complete odontometric description for the studied teeth, as more than two hundred parameters are obtained on each tooth section. Though there is objective evidence that automated digital odontometry (aDo) can serve an effective instrument in morphological description of teeth. And it is difficult to pick a very specific parameter for description of sharpened cusps with bent tips; more likely it is a matter of combining various data for creating a complete morphological profile of a tooth, or groups of teeth.

\subsection{Anthropological considerations}

Though there might be an opinion that in terms of anthropological studies, comparisons of Upper Palaeolithic upper second molars with third upper molar dated to Bronze Age, or any other involvement of third molars odontological analysis, is not reliable. The reason is in very high degree of variability of third molar morphology (it can be clearly seen on dental arch scan from Chernovaya, if you compare with each other antimere wisdom teeth), and expression of any traits on them cannot be considered as a consistent feature. On the other hand probably due to morphological variability we have revealed a rare and presumably archaic feature on the third molar. In fact, there are examples of extensive studies in dental anthropology based on geometric morphometric analysis involving the above-mentioned teeth (Gomez-Robles et al., 2012). However we should mention that the comparisons between second and third molars performed in the current study are mainly related to $3 \mathrm{D}$ image analysis method based on automated algorithms objectively reflecting dental morphology, not to historically or anthropologically referred interpretations (though we can't exclude completely that they in fact are correct).

\subsection{Prospects}

The presented odontometric data requires implementation of more sophisticated and up-to-date methods of analysis, including self-learning algorithms. The measurement method itself is developing in the direction of increase of diversity in obtaining odontometric parameters, including parameters referring not only teeth but their closure as well. However, teeth themselves have a potential for more profound odontometric studies, especially and largely due to such imaging techniques as micro-CT and corresponding image processing techniques.

\section{CONCLUSIONS}

Automated digital odontometry (aDo) - based on combination of 3D surface and 2D contour analysis with morphological interpretations - provides for objective studies referred to dental morphology and its relatively rare cases. This includes features which traditionally have been described through non-metric methods on unique anthropological findings reflecting archaic trait expression.

\section{ACKNOWLEDGEMENTS}

The current research is supported by Grant 17-29-04509 of Russian Foundation for Basic Research (RFBR).

\section{REFERENCES}

Bailey et al., 2014. Bailey, Sh., Benazzi, S., Souday, C., Astorino, C., Paul, K., Hublin, J-J. Taxonomic differences in deciduous upper second molar crown outlines of Homo sapiens, Homo neanderthalensis and Homo erectus. Journal of human evolution. 72. 10.1016/j.jhevol.2014.02.008.

Berthaume et al., 2019. Berthaume MA, Winchester J, Kupczik K (2019) Ambient occlusion and PCV (portion de ciel visible): A new dental topographic metric and proxy of morphological wear resistance. PLOS ONE 14(5): e0215436. https://doi.org/10.1371/journal.pone.0215436

Choi et al., 2019. Choi, G., Chan, H.L., Yong, R., Ranjitkar, S., Brook, A., Townsend, G., Chen, K., Lui, L.M. Tooth morphometry using quasi-conformal theory. arXiv:1901.01651v1 [cs.CV]

Dykes and Pilbrow, 2019. Dykes, S. and Pilbrow, V. A mathematical landmark-based method for measuring worn molars in hominoid systematics. PeerJ Vol. 7: e6990 http://doi.org/10.7717/peerj.6990

Gaboutchian et al., 2019. Gaboutchian A.V., Knyaz V.A., Leybova N.A., Petrosyan G.R., Simonyan H.Y. and S.V. Vasilyev. Application Of Photogrammetric Techniques In Palaeoodontological Studies Trough Automated Digital Shape Analysis Of Human Teeth. Int. Arch. Photogramm. Remote Sens. Spatial Inf. Sci., XLII-2/W12, 75-80, https://doi.org/10.5194/isprs-archives-XLII-2-W12-75-2019, 2019.

Gaboutchian and Knyaz, 2019. Gaboutchian, A. V. and Knyaz, V. A.: 3D Images For Automated Digital Odontometry, Int. Arch. Photogramm. Remote Sens. Spatial Inf. Sci., XLII2/W18, 53-57, https://doi.org/10.5194/isprs-archives-XLII-2W18-53-2019, 2019. 
Ghizlanzioni et al., 2017. Ghislanzoni L.H., Lione, R., Cozza P., Franchi L. Measuring 3D shape in orthodontics through geometric morphometrics. Progress in Orthodontics, 2017. 18. 10.1186/s40510-017-0194-9

Gomez-Robles et al., 2012. Gomez-Robles A., Castro J., Martinón-Torres M., Prado-Simón .L, Arsuaga J. A Geometric Morphometric Analysis of Hominin Upper Second and Third Molars with Particular Emphasis on European Pleistocene Populations. Journal of human evolution 2012. 63. 512-26. 10.1016/j.jhevol.2012.06.002

Guy et al., 2013. Guy F., Gouvard F., Boistel R., Euriat A., Lazzari V.. Prospective in (Primate) Dental Analysis through Tooth 3D Topographical Quantification. PloS one, 2013. 8. e66142. 10.1371/journal.pone.0066142.

Khera et al., 1990. Khera, S.C., Carpenter, C.W., Vetter, J.D., Staley, R.N. Anatomy of cusps of posterior teeth and their fracture potential. J. Prosthet. Dent. 64, 139-147.

Knight-Sadler and Fiorenza, 2017. Knight-Sadler J., Fiorenza L., Tooth Wear Inclination in Great Ape Molars. Folia Primatologica, 2017. 88. 223-236. 10.1159/000478775.

Martin, 1983. Martin L.B. Relationship of the Later Miocene Hominoidea. PhD Dissertation, University College London.

Martin et al., 2017. Martin, R., Hublin, J.-J., Gunz, P., Skinner, M. (2017). The morphology of the enamel-dentine junction in Neanderthal molars: Gross morphology, non-metric traits, and temporal trends. Journal of Human Evolution. 103. 20-44. 10.1016/j.jhevol.2016.12.004.

Ortiz et al., 2012. Ortiz A., Skinner M., Bailey Sh., Hublin JJ., Carabelli's trait revisited: An examination of mesiolingual features at the enamel-dentine junction and enamel surface of Pan and Homo sapiens upper molars. Journal of human evolution, 2012. 63. 586-96. 10.1016/j.jhevol.2012.06.003.

Oxillia et al., 2017. Oxilia, G., Bortolini, E., Martini, S., Papini, A.,Boggioni, M., Buti, L., Figus, C., Sorrentino, R.,Townsend, G., Kaidonis, J., Fiorenza, L., Cristiani, E., Kullmer, O., MoggiCecchi, J., Benazzi, S. The physiological linkage between molar inclination and dental macrowear pattern. American Journal of Physical Anthropology. 166. 10.1002/ajpa.23476.

Peckmann et al., 2015. Peckmann, T., Meek, S., Dilkie, N., Mussett, M. (2015). Sex Estimation Using Diagonal Diameter Measurements of Molar Teeth in African American populations. Journal of forensic and legal medicine. 36. 70-80. 10.1016/j.jflm.2015.09.001.

Sassani et al., 2018. Sassani, S., Patel, D., Farella, M., Henneberg, M., Ranjitkar, S., Yong, R., Swindells, S., Brook, A. Variation in tooth crown size and shape are outcomes of the complex adaptive system associated with the tooth number variation of hypodontia. International Journal of Design \& Nature and Ecodynamics. 13. 114-120. 10.2495/DNE-V13-N1114-120.

Song et al., 2017. Song, J.-W., Leesungbok, R., Park, S.-J., Chang, S., Ahn, S.-J., Lee, S.-W. Analysis of crown size and morphology, and gingival shape in the maxillary anterior dentition in Korean young adults. The Journal of Advanced Prosthodontics. 9. 315. 10.4047/jap.2017.9.4.315

Skinner et al., 2010. Skinner, M., Evans, A., Smith, T., Jernvall, J., Tafforeau, P., Kupczik, K., Olejniczak, A., Rosas, A., Radovcić, J., Thackeray, F., Toussaint, M., Hublin, J.-J. (2010). Brief Communication: Contributions of Enamel-Dentine Junction Shape and Enamel Deposition to Primate Molar Crown Complexity. American journal of physical anthropology. 142. 157-63. 10.1002/ajpa.21248.

Smith et al., 2009. Smith R, Zaitoun H, Coxon T, Karmo M, Kaur G, Townsend G, Harris E, Brook A. Defining new dental phenotypes using 3-Dimage analysis to enhance discrimination and insights into biological processes. Arch Oral Biol. 2009;54S:S118-25

Smith et al., 2012. Smith, T., Olejniczak, A., Zermeno, J., Tafforeau, P., Skinner, M., Hoffmann, A., Radovcic, J., Toussaint, M., Kruszynski, R., Menter, C., Moggi-Cecchi, J., Glasmacher, U., Kullmer, O., Schrenk, F., Stringer, Ch., Hublin, J-J. Variation in enamel thickness within the genus Homo. Journal of human evolution. 62. 395-411. 10.1016/j.jhevol.2011.12.004

Taduran, 2012. Taduran, R.J. (2012). Sex Determination from Maxillary and Mandibular Canines of the Filipino Population. New directions in dental anthropology: paradigms, methodologies and outcomes / edited by Grant Townsend, Eisaku Kanazawa and Hiroshi Takayama. pp 81-91. 10.1017/UPO9780987171870.008

Vasilyev, 2000. Vasilyev S.V., 2000, "Craniotrigonometry of skulls from grave 2", In: Homo Sungerensis, Verkhnepaleoliticheskiy chelovek: evolutsionnye i ekologicheskiye aspekty issledovaniya, Moscow, Nauchniy Mir, pp 253-254

Zanolli et al., 2018 Zanolli C, Martinón-Torres M, Bernardini F, Boschian G, Coppa A, et al. (2018) The Middle Pleistocene (MIS 12) human dental remains from Fontana Ranuccio (Latium) and Visogliano (Friuli-Venezia Giulia), Italy. A comparative high resolution endostructural assessment. PLOS ONE 13(10): e0189773. https://doi.org/10.1371/journal.pone.0189773

Zubov, 2000 Zubov A.A,. 2000 (in Russian) "Morfologicheskoe issledovanie detey iz sungirskogo pogrebeniya 2", In: Homo Sungerensis, Verkhnepaleoliticheskiy chelovek: evolutsionnye i ekologicheskiye aspekty issledovaniya, Moscow, Nauchniy Mir, pp 256-270. 